\title{
Optoelectric Properties of GaInP p-i-n Solar Cells with Different i-Layer Thicknesses
}

\author{
Tsung-Shine Ko, ${ }^{1}$ Der-Yuh Lin, ${ }^{1}$ You-Chi He, ${ }^{1}$ Chen-Chia Kao, ${ }^{1}$ Bo-Yuan Hu, \\ Ray-Hua Horng, ${ }^{2}$ Fan-Lei Wu, ${ }^{2}$ Chih-Hung Wu, ${ }^{3}$ and Yu-Li Tsai ${ }^{3}$ \\ ${ }^{1}$ Department of Electronic Engineering, National Changhua University of Education, No. 1, Jin-De Road, Changhua 500, Taiwan \\ ${ }^{2}$ Department of Materials Science and Engineering, National Chung Hsing University, 250 KuoKuang Road, Taichung 402, Taiwan \\ ${ }^{3}$ High Concentration Photovoltaic Project, Institute of Nuclear Energy Research, 4th Floor, No. 90, Luke 5th Road, \\ Lujhu District, Kaohsiung 821, Taiwan
}

Correspondence should be addressed to Der-Yuh Lin; dylin@cc.ncue.edu.tw

Received 9 December 2014; Revised 29 January 2015; Accepted 29 January 2015

Academic Editor: Shyh-Jer Huang

Copyright (c) 2015 Tsung-Shine Ko et al. This is an open access article distributed under the Creative Commons Attribution License, which permits unrestricted use, distribution, and reproduction in any medium, provided the original work is properly cited.

\begin{abstract}
The optoelectric properties of GaInP p-i-n solar cells with different intrinsic layer (i-layer) thicknesses from 0.25 to $1 \mu \mathrm{m}$ were studied. Both emission intensity and full width at half maximum features of the photoluminescence spectrum indicate that the optimum i-layer thickness would be between 0.5 and $0.75 \mu \mathrm{m}$. The integrated current results of photocurrent experiment also point out that the samples with 0.5 to $0.75 \mu \mathrm{m}$ i-layer thicknesses have optimum value around $156 \mathrm{nA}$. Electroreflectance measurements reveal that the built-in electric field strength of the sample gradually deviates from the theoretical value larger when i-layer thickness of the sample is thicker than $0.75 \mu \mathrm{m}$. $I$ - $V$ measurements also confirm crystal quality for whole samples by obtaining the information about short currents of photovoltaic performances. A series of experiments reflect that thicker i-layer structure would induce more defects generation lowering crystal quality.
\end{abstract}

\section{Introduction}

Solar cell devices play an important role in renewable energies which convert solar energy directly into electricity. In recent years, tandem structures have been developed for high efficiency applications. These were stacked by multiple subcells with different band gaps to absorb the sun light in different spectral ranges and convert it into electric power. Multijunction III-V tandem structure solar cells such as GaInP/ GaInAs/Ge triple junction cells have attracted increasing attention for their very high conversion efficiencies $[1,2]$. However, the high cost of III-V tandem cells has been the main impediment for their widespread applications. Another kind of basic solar cell structures is $\mathrm{p}-\mathrm{i}-\mathrm{n}$ structure, which consists of $\mathrm{p}$ - and $\mathrm{n}$-doped regions on top and bottom layers and an intrinsic layer (i-layer) in middle one. It provides a simple way to improve the absorption ability with a thick intrinsic region. It is also well known that the built-in electric field plays a critical role in solar cell devices; however, it is difficult to detect by electric methods directly and less studies have been reported [3]. In addition, the different thicknesses of an i-layer would be studied in detail because the thicker i-layer may induce more defects and lower the built-in electric field. Modulation spectroscopy is a powerful tool for studying optical fine structures in semiconductor devices and materials [4-9]. In order to evaluate the i-layer quality, a systematic optical characterization of thickness and built-in electric field must be clarified for giving us information in order to optimize the power conversion efficiency. These parameters are also desirable for improving the tandem cell design and improving the quality of the epitaxial layers.

In this study, we performed photoluminescence (PL) and photocurrent $(\mathrm{PC})$ spectra measurements to detect the energy band gap of GaInP layers and understand the absorption behaviors of these devices. We also measure the period of Franz-Keldysh oscillations (FKOs) using electroreflectance 


\begin{tabular}{|c|}
\hline $\mathrm{p}$-GaAs contact \\
\hline $\mathrm{p}$-AlGaInP window \\
\hline $\mathrm{p}$-GaInP emitter \\
\hline i-GaInP \\
\hline $\mathrm{n}$-GaInP base \\
\hline $\mathrm{n}$-AlGaInP BSF \\
\hline $\mathrm{n}$-GaAs buffer \\
\hline $\mathrm{n}$-GaAs substrate \\
\hline
\end{tabular}

FIGURE 1: The main structure of GaInP p-i-n solar cells.

(ER) spectroscopy to reveal the built-in electric field strength. Consequently, the ER results could determine whether the ilayer thickness is suitable or not for device design. Furthermore, the $I-V$ measurements for the devices could provide many important pieces of information and optoelectric characteristics such as short current $\left(I_{\mathrm{sc}}\right)$, open circuit $\left(V_{\mathrm{oc}}\right)$, fill factor $(\mathrm{FF})$, efficiency $(\eta)$, series resistance $\left(R_{s}\right)$, and shunt resistance $\left(R_{\mathrm{sh}}\right)$. Comparing the information collected by the different techniques, a clear picture of the built-in electric field and an optimized i-layer thickness in InGaP p-i-n solar cells will be presented in the following content.

\section{Experimental Methods}

A series of GaInP p-i-n solar cells with different i-layer thicknesses were grown on (100) GaAs substrates by low pressure metal-organic chemical vapor deposition system, and the layered structure is schematically presented in Figure 1. On the top of the $n-G a A s$ substrate, there is an $n-G a A s$ buffer layer, followed by an n-AlGaInP back surface field layer $(0.1 \mu \mathrm{m})$ and a $\mathrm{p}-\mathrm{i}-\mathrm{n}$ structure consisting of an $\mathrm{n}$-GaInP base $(0.3 \mu \mathrm{m})$, an i-GaInP layer, and a p-GaInP emitter layer $(0.1 \mu \mathrm{m})$, followed by an AlGaInP window layer $(0.03 \mu \mathrm{m})$ and a $\mathrm{p}-\mathrm{GaAs}$ contact layer $(0.3 \mu \mathrm{m})$. The composition ratios are about $\mathrm{Ga}_{0.5} \mathrm{In}_{0.5}$ for i-layer and $\left(\mathrm{Al}_{0.35} \mathrm{Ga}_{0.65}\right)_{0.5} \mathrm{In}_{0.5} \mathrm{P}$ for back surface field layer. According to growth rate and period information, the thicknesses of the i-layers for the four samples that could be calculated are $0.25,0.5,0.75$, and $1 \mu \mathrm{m}$, respectively. We symbolized them as samples A, B, C, and D. The doping concentrations for the emitter and base layers of all samples are $2 \times 10^{18}$ and $3 \times 10^{17} \mathrm{~cm}^{-3}$, respectively.

PL spectra were performed by using a $100 \mathrm{~mW}$ diode pump solid state laser with wavelength of $532 \mathrm{~nm}$ for studying the composition and crystal quality of the GaInP layer. A silicon detector and a $0.25 \mathrm{~m}$ monochromator equipped with a lock-in amplifier were used to record the optical intensity of the PL spectra. For PC spectra system, the monochromatic light coming from a $150 \mathrm{~W}$ halogen lamp was filtered by a monochromator and then focused on the sample surface by a lens. The photocurrent induced by the monochromatic light was measured by a Keithley 6485 picoampere meter. In order to detect the built-in electric field in the solar cells,

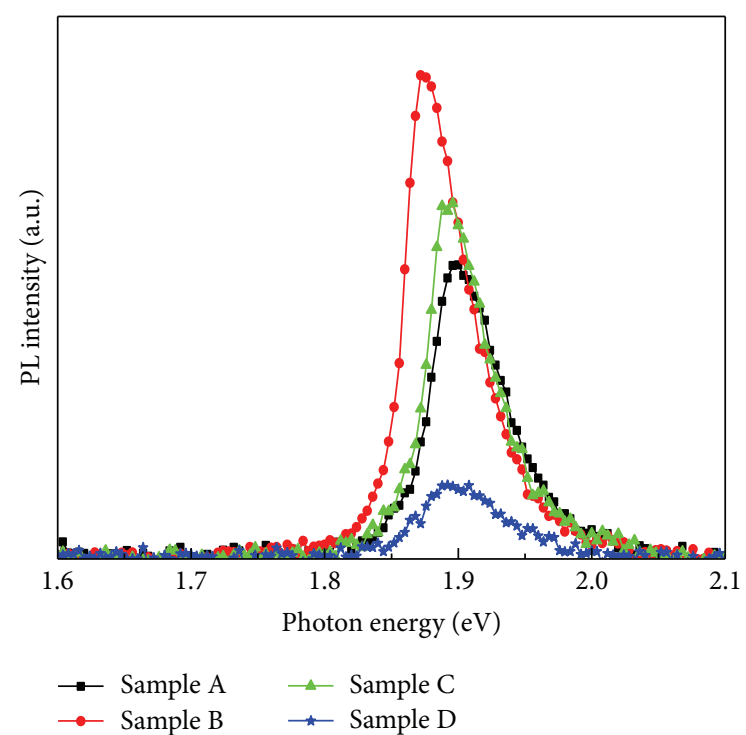

FIgURE 2: The room temperature PL spectra of samples A D.

ER spectra were performed at various reversed biases $[5,6]$. The modulation voltage is $0.3 \mathrm{~V}$ and the system configuration is similar to the reflectivity measurement and the detailed experimental setup has been described elsewhere [10, 11]. Furthermore, a solar simulator (SS150 fully reflective solar simulator) was used to obtain the $I-V$ characteristics.

\section{Results and Discussion}

The PL spectra of samples A, B, C, and D with peaks around $1.9 \mathrm{eV}$ are shown in Figure 2. For these four samples, the PL signals mainly come from the i-GaInP layer, because the high doping will induce nonradiative centers and weaken the luminescent efficiency in $\mathrm{p}$ - and $\mathrm{n}$-doping layers. The PL intensity was enhanced as the i-layer thickness increased from 0.25 to $0.5 \mu \mathrm{m}$. Since main radiative recombination centers located in the thicker i-layer, the PL intensity of sample C is lower than that of sample B although it had a thicker i-layer. In general, PL intensity reflects the probability of a radiative recombination and gives us an evaluation reference for the crystal quality. A high crystalline quality layer exhibits strong PL intensity; however, a layer with poor crystalline quality shows a weak emission because most of the photo generated carriers are recombined by nonradiative recombination centers. Therefore, this result could be probably attributed to the generation of defects in the thick i-layer of sample C. Comparing with the PL peak intensity of samples A, B, and $\mathrm{C}$, the intensity of sample D is quite small. This weak PL intensity indicates that the i-layer quality is also not good due to many defects that have been generated in sample D, which affects the efficiency of the solar cell. Furthermore, we also noted that the full width at half maximum (FWHM) value of the PL spectra is $18.9,19.3,20.1$, and $25.0 \mathrm{~nm}$ for four samples, respectively. Sample D has the largest FWHM value among all samples, which is another evidence showing that the crystalline quality of the i-layer could be degraded 




Figure 3: The PC spectra of samples A D.

as the layer thickness increases beyond a critical thickness. In addition, the PL peaks of the four samples are at around $1.88 \mathrm{eV}$ closely. According to the relationship between energy band gap and alloy composition presented in the previous literatures $[12,13]$, the alloy compositions $x$ of $\mathrm{Ga}_{x} \operatorname{In}_{1-x} \mathrm{P}$ for samples A to D are determined to be $0.58,0.54,0.58$, and 0.58 , respectively, by using the following equation:

$$
E_{g}=1.32+0.7 x+0.68 x^{2} .
$$

The effect of i-layer thickness on PC spectra is shown in Figure 3. For four samples, the photo-induced currents all rise abruptly at $1.9 \mathrm{eV}$ indicating the absorption edge positions of the solar cells. The PC peak currents are 124, 152, 156, and $147 \mathrm{nA}$ for samples A to D, respectively, while the integrated values are $63,76,71$, and $66 \mathrm{nA}$. In comparison with sun illumination, the low integrated values here is that the samples were measured under single frequent light filtered by the monochromator. The peak and integrated values of sample A are smaller than those of the other samples due to the fact that the i-layer is too thin to absorb all light. As the thickness of the i-layer increases, a larger photocurrent generation could be expected. Obviously, the PC values for samples B and C were improved among all samples. However, with the i-layer thickness continuously increasing, the PC results tend to saturate and then decrease due to the formation of a high density point defect in the thick i-layer, which are also consistent with the above PL results. Both the PC and PL results indicate that the optimum i-layer thickness should be between 0.5 and $0.75 \mu \mathrm{m}$. Furthermore, we analyzed the peak shifts between the PL peak and he PC absorption edge carefully. It is obvious to find that the shifts from sample A to sample D are small and still in a reasonable range $(\sim 20 \mathrm{meV})$. These shifts are probably due to slight difference in composition or thickness uniformity because the measurement positions are not totally the same between PL and PC experiments.

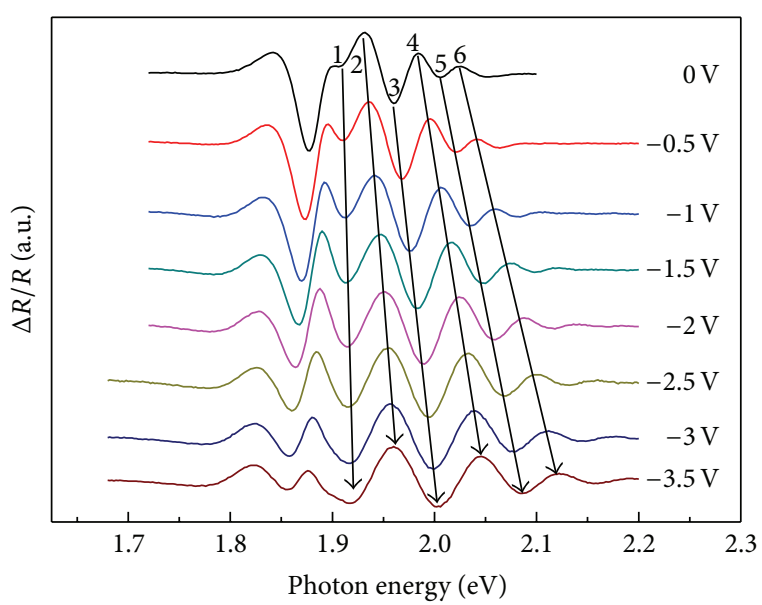

FIGURE 4: The ER spectra of sample A measured at different reverse biases from 0 to $3.5 \mathrm{~V}$.

In general, a small perturbation was triggered for modulation spectroscopy using an external voltage or temperature change to create a periodic variation on the band gap; afterward, the optical absorption coefficients and the dielectric coefficients would be changed as well. The basic principle of ER is to take the derivative of the optical spectrum with respect to a modulation of an electric field. The absorption transitions of carriers could be resolved and other background signals of the ER system could be diminished using a lock-in amplifier to detect the small variation in the reflected light of probe beam. ER system has been widely utilized to reveal the transition energies of quantum wells and the built-in electric fields in many kinds of junction structures [14]. Based on the Franze and Keldysh theory [15], Shen et al. proposed a precise evaluation of the electric field strength by analyzing the period of FKOs existing in ER spectra [16, 17]. Due to the advantages of noncontact and nondestructive methods, these efforts allow modulation spectroscopy a unique method for detecting the built-in electric field in diode and transistor structures [18-20]. For $\mathrm{p}-\mathrm{i}-\mathrm{n}$ solar cells, a high electric field is built across the i-layer by the Fermi level difference between the $\mathrm{p}$ - and $\mathrm{n}$-doped layers. This built-in electric field is the engine for driving the electron-hole pairs induced by solar light out of the cells and generating electric power. Therefore, we utilized ER measurement to obtain the built-in electric field in the i-layer with different thicknesses for the all samples. In Figure 4, we present the ER spectra of sample A at different reverse biases and calculate the built-in electric field strength $F$ from FKO periods. The ER line shape is given approximately by [21]

$$
\frac{\Delta R}{R} \propto \exp \left(\frac{-\Gamma\left(E-E_{g}\right)^{1 / 2}}{(\hbar \Omega)^{3 / 2}}\right) \cos \left(\frac{2}{3}\left[\frac{E-E_{g}}{\hbar \Omega}\right]^{3 / 2}+\theta\right),
$$

where $\Delta R / R$ is normalized reflectance difference, $E$ is photon energy, $\Gamma$ is a damping parameter, $\hbar \Omega$ is electrooptic energy, 


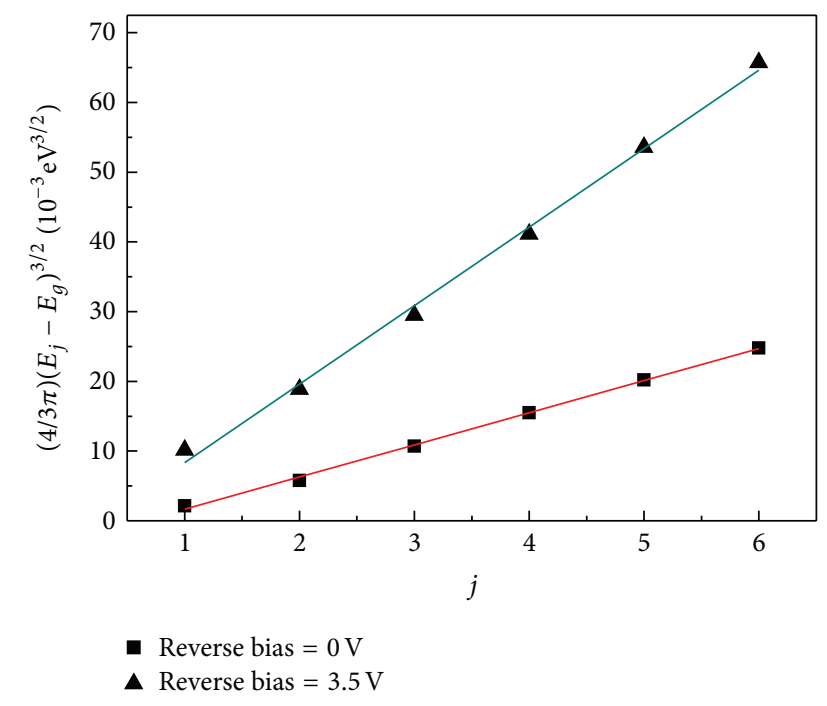

FIgURE 5: The photon energy of the $j_{\text {th }}$ as a function of the index $j$ for ER analysis of sample A.

and $\theta$ is a phase factor. The cosine term has extrema at energies $E_{j}$ given by

$$
\left[E_{j}-E_{g}\right]^{3 / 2}=\frac{3}{2}[\hbar \Omega]^{3 / 2}(j \pi-\theta) \quad j=0,1,2,3, \ldots,
$$

where $j$ is the index number of the $j_{\text {th }}$ extremum. The carriers have a resulting electrooptic energy:

$$
\hbar \Omega=\left(\frac{e^{2} \hbar^{2} F^{2}}{8 \mu}\right)^{1 / 3},
$$

where $e$ is the electronic charge and $\mu$ is the inter band reduced effective mass in the field direction. Figure 4 displays the ER spectra of sample A measured at different reverse biases between 0 and $3.5 \mathrm{~V}$. The first feature below $1.9 \mathrm{eV}$ shows the direct energy band gap $\left(E_{g}\right)$ of the i-layer, while features above $1.9 \mathrm{eV}$ are the FKO features. Their photon energies are labeled as 1-6 and guided by the lines with arrows in the end, shift toward high energy with increasing reverse bias due to the increase of the built-in electric field. Figure 5 shows the photon energy of the $j_{\text {th }}$, which is defined as $(4 / 3 \pi)\left(E_{j}-E_{g}\right)^{3 / 2}$, and plots as a function of the index $j$ for further ER analysis of sample A. The results indicate two straight lines, squares for zero bias and triangles for $3.5 \mathrm{~V}$ reverse bias which we provide for the samples. From the slope of this straight line and (4), the built-in electric fields were determined to be $90 \mathrm{kV} / \mathrm{cm}$ at zero bias and $223 \mathrm{kV} / \mathrm{cm}$ at $3.5 \mathrm{~V}$ reverse bias, respectively. This built-in electric field in the i-layer of a $\mathrm{p}-\mathrm{i}-\mathrm{n}$ structure is mainly determined by the doping levels in n-, p-layers, and the thickness of the ilayer. Because the doping levels are quite high which is $2 \times$ $10^{18} \mathrm{~cm}^{-3}$ in the $\mathrm{p}$ layer and $3 \times 10^{17} \mathrm{~cm}^{-3}$ in the $\mathrm{n}$ layers, $\mathrm{a}$ lot of electrons and holes are accumulated at both sides of the i-layer and the Fermi level is very close to conduction and valence bands in $\mathrm{n}$ - and p-type layers, respectively. Therefore, the built-in electric field at zero bias can be estimated by

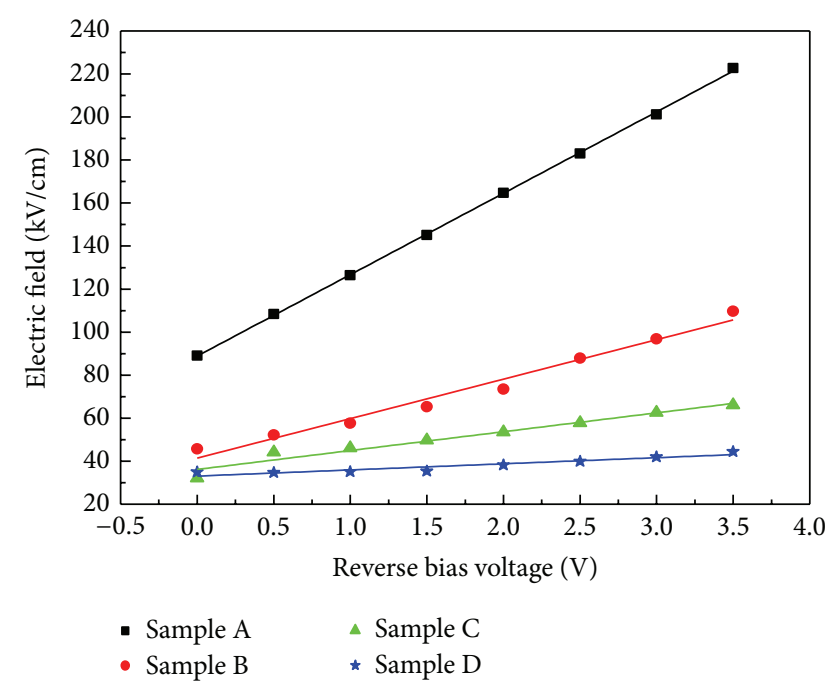

Figure 6: The fitting built-in electric fields of samples A D from the ER results under various biases.

TABLE 1: Increasing rate of built-in electric field strength for samples A D.

\begin{tabular}{lcccc}
\hline \multicolumn{5}{c}{ Increasing rate of built-in electric field $(\mathrm{kV} / \mathrm{cm})$} \\
& $\mathrm{A}$ & $\mathrm{B}$ & $\mathrm{C}$ & $\mathrm{D}$ \\
\hline $\begin{array}{l}\text { Theoretical } \\
\text { value }\end{array}$ & 40 & 20 & 13.3 & 10 \\
$\begin{array}{l}\text { Experimental } \\
\text { value }\end{array}$ & 38 & 18 & 10 & 3 \\
\hline
\end{tabular}

the energy band gap of InGaP divided by i-layer thickness. On the basis of this simple calculation, the theoretical value of the built-in electric field is $86.3 \mathrm{kV} / \mathrm{cm}$ for sample A. This theoretical value of the built-in electric field matches well with the measured result.

Figure 6 shows the built-in electric fields of samples A to $\mathrm{D}$ which are fitted from the ER spectra results under various biases. These built-in electric fields results reveal a linear accession trend with increasing the reverse bias. The corresponding accession values of built-in electric fields are $38,18,10$, and $3 \mathrm{kV} / \mathrm{cm}$ for samples A to $\mathrm{D}$, respectively. The reverse voltage could be applied on the $\mathrm{i}$-GaInP due to the small leakage current. Therefore, the theoretical accession value of the built-in electric field could be estimated by using the applied voltage divided by the thickness of $\mathrm{i}$-GaInP layer. The theoretical value of the increased electric field when one-volt voltage is provided should be 40.0, 20.0, 13.3, and $10.0 \mathrm{kV} / \mathrm{cm}$ for samples A to $\mathrm{D}$, respectively. The theoretical and experimental values are listed in Table 1 . It could be found that the experimental values match well with the theoretical values when the thickness of the i-GaInP layer is small, such as samples A and B, but gradually deviate from the theoretical value as the thickness is larger than $0.75 \mu \mathrm{m}$. For sample D, the accession value is only one-third of the theoretical value. According to this result, it is clear that the crystal quality of the thin i-GaInP layer is quite good and no defect dipoles existing in this layer, results in that all of the reverse bias has 


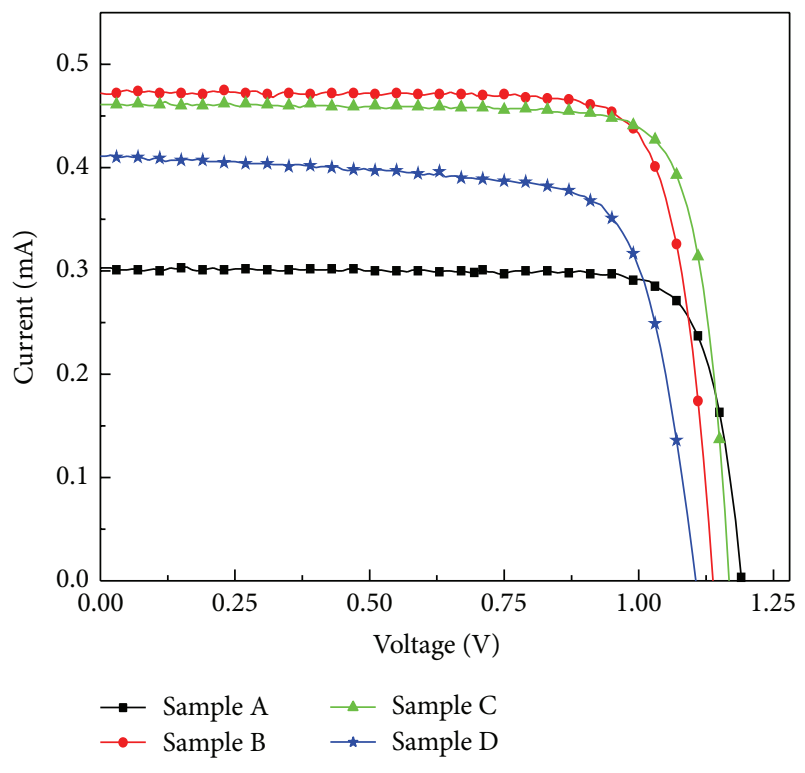

FIgURE 7: The $I-V$ characteristics of samples A D obtained under sun illumination.

been applied on this layer. On the other hand, the i-GaInP layer quality of sample $\mathrm{D}$ is not good enough due to a large number of point defects, which became charged dipoles as the reverse bias was applied and reduced the accession value of the electric field $[22,23]$.

Figure 7 shows the $I-V$ characteristics of samples A to D obtained under sun illumination. A lot of parameters relating to solar cell circuit could be extracted from $I-V$ curves such as $I_{\mathrm{sc}}, V_{\mathrm{oc}}, R_{\mathrm{sh}}$, and $R_{\mathrm{s}}$ [24-26]. $I_{\mathrm{sc}}$ represents the maximum current at short circuit circumstance and reflects the capability of generating current. We can observe that samples B and C have high values of $I_{\mathrm{sc}}$, while samples A and $\mathrm{D}$ have low $I_{\mathrm{sc}}$. However, the $I_{\mathrm{sc}}$ was measured by a solar simulator consisting of the whole sun spectra, and their results are similar to the integration of the PC spectra. The integrated values for samples A to D are $63,76,71$, and $66 \mathrm{nA}$, respectively. This result indicates the same trend like that we have observed in $I_{\mathrm{sc}}$ values. We could further confirm that the suitable i-layer thickness for good performance is between 0.5 and $0.75 \mu \mathrm{m}$. Štulík and Singh proposed the influence of defects on $I_{\text {sc }}$ for Si based solar cell indicating worse i-layer crystal quality would cause lower $I_{\mathrm{sc}}$ value [27]. Therefore, the low $I_{\mathrm{sc}}$ values for samples A and D reflect many defects existing in the i-layer with a unsuitable thickness.

The open circuit voltage, $V_{\mathrm{oc}}$, is the maximum voltage available from a junction solar cell, and it occurs at zero currents. The $V_{\mathrm{oc}}$ values were obtained from the intersection of the $I-V$ curve and the horizontal axis voltages; these values are $1.19,1.14,1.17$, and $1.11 \mathrm{~V}$ for samples $\mathrm{A}$ to $\mathrm{D}$. For single-junction solar cells, $V_{\text {oc }}$ could be determined as $V_{\mathrm{oc}}=$ $\left(n k_{B} T / q\right) \ln \left(J_{\text {sc }} / J_{o}+1\right)$, where $k T / q$ is the thermal voltage, $n$ is the ideality factor, $J_{o}$ is saturation current, and $J_{\mathrm{sc}}$ is short circuit current density. In general, the saturation current density depends on recombination in the solar cell; therefore, $V_{\text {oc }}$ is a measure of the amount of recombination in the device.
TABLE 2: Photovoltaic performances of samples A D.

\begin{tabular}{lcccc}
\hline Sample & A & B & C & D \\
\hline$V_{\text {oc }}(\mathrm{V})$ & 1.19 & 1.14 & 1.17 & 1.11 \\
$I_{\text {sc }}(\mathrm{mA})$ & 0.30 & 0.47 & 0.46 & 0.41 \\
$V_{\max }(\mathrm{V})$ & 1.02 & 0.98 & 1.03 & 0.93 \\
$I_{\max }(\mathrm{mA})$ & 0.29 & 0.44 & 0.43 & 0.36 \\
$P_{\max }(\mathrm{mW})$ & 0.30 & 0.43 & 0.44 & 0.34 \\
$\mathrm{FF}(\%)$ & 82 & 81 & 82 & 74 \\
$\eta(\%)$ & 3.28 & 4.82 & 4.88 & 3.76 \\
$R_{\mathrm{sh}}(\mathrm{K} \Omega)$ & 147 & 137 & 107 & 82 \\
$R_{s}(\Omega)$ & 123 & 127 & 129 & 246 \\
\hline
\end{tabular}

For sample $\mathrm{D}$, the $V_{\text {oc }}$ reduction is obvious, which may be related to the enhanced generation of the saturation current determined by various mechanisms such as the recombination current of defects or diffusion current [28]. Furthermore, the two equivalent resistances connected in series $\left(R_{s}\right)$ and in shunt $\left(R_{\mathrm{sh}}\right)$ also can be extracted from the slope of $I-V$ curves at open circuit and short circuit circumstances, respectively. The results have been summarized in Table 2. For an efficient solar cell, low $R_{s}$ and large $R_{\mathrm{sh}}$ features are necessary which decrease power loss of solar cell in addition to affecting FF. Table 2 shows that the $R_{s}$ increases a little from samples A to $\mathrm{C}$ and causes a dramatic jump for sample D. We think that the increase in $R_{s}$ is responsible for the increase of the i-layer thickness [29]. For sample D, a lot of point defects in the i-layer resist the current flow and result in a high series resistance. The resistance of $R_{\mathrm{sh}}$ decreases a little from samples A to $\mathrm{C}$ and decreases dramatically for sample $\mathrm{D}$. This decrease of $R_{\mathrm{sh}}$ is responsible for the increase of the nonradiative recombination centers coming from point defects in the i-layer. In general, the fill factor (FF) value could reflect the performance of solar cell. When FF is closed to $100 \%$ which means the solar cells possess ideal $I-V$ characteristic and allow maximum power delivered to the load, the FF is defined as the ratio of maximum power to the product of $I_{\mathrm{sc}}$ and $V_{\mathrm{oc}}$. Either a large $R_{s}$ or a small $R_{\mathrm{sh}}$ will reduce the FF. According to the information in Table 2 we organized, the relevant results of sample A show low $R_{s}$ and large $R_{\mathrm{sh}}$ features reflecting a good FF property. In contrast, a poor FF property of the sample $\mathrm{D}$ could be reasonable due to a high $R_{s}$ and a low $R_{\mathrm{sh}}$.

Another key performance characteristic of a solar cell is the efficiency $\eta$, which is the ratio of maximum out power to the incidental light power. Table 2 shows the $\eta$ values for samples A to D are between 3 and 5\%. According to a previous literature [30], Shu et al. proposed that the conversion efficiency of GaInP p-i-n solar cells could achieve around $5 \%$ with $1 \mathrm{~mA} / \mathrm{cm}^{2}$ photocurrent density generated using similar measurement methods to ours. In our cases, no antireflection coating layer applied in our devices is probable a reason for low efficiency. From the data shown in Table 2, it could be found that samples B and C have better efficiency than samples A and D. From these key performance characteristics, we can understand that the optimized thickness of the i-layer is critical and in the range around 0.5 to $0.75 \mu \mathrm{m}$. The crystal quality of the i-layer is dependent on the thickness 
of the i-layer. Both the performance and the built-in electric field of solar cells actually rely on a suitable thickness of i-layer with high quality.

\section{Conclusions}

In conclusion, we have presented the study on built-in electric fields and optical properties of GaInP p-i-n solar cells with different i-layer thicknesses. A series of experiments determined the built-in electric field strengths and i-layer quality for all samples and confirmed that the optimized ilayer thickness is around 0.5 to $0.75 \mu \mathrm{m}$. For the sample with thinner i-layer thickness, solar cells could not absorb all of the sun light efficiently. Therefore, the short circuit current and output power would be low. In addition, a lot of point defects are generated in the sample with thicker layer and the built-in electric field is not high enough to drive out all of photo-induced current.

\section{Conflict of Interests}

The authors declare that there is no conflict of interests regarding the publication of this paper.

\section{Acknowledgment}

The authors would like to acknowledge the financial support of the National Science Council, Taiwan, under Contract NSC 100-2112-M-018-002.

\section{References}

[1] R. R. King, D. C. Law, K. M. Edmondson et al., “ $40 \%$ efficient metamorphic GaInP/GaInAs/Ge multijunction solar cells," Applied Physics Letters, vol. 90, no. 18, Article ID 183516, 2007.

[2] D. Shahrjerdi, S. W. Bedell, C. Ebert et al., "High-efficiency thin-film InGaP/InGaAs/Ge tandem solar cells enabled by controlled spalling technology," Applied Physics Letters, vol. 100, no. 5, Article ID 053901, 2012.

[3] I. Serdiukova, C. Monier, M. F. Vilela, and A. Freundlich, "Critical built-in electric field for an optimum carrier collection in multiquantum well p-i-n diodes," Applied Physics Letters, vol. 74, no. 19, pp. 2812-2814, 1999.

[4] F. H. Pollak and H. Shen, "Modulation spectroscopy of semiconductors: bulk/thin film, microstructures, surfaces/interfaces and devices," Materials Science and Engineering: R: Reports, vol. 10, no. 7-8, pp. 275-374, 1993.

[5] R. Henninger, J. Klaer, K. Siemer, J. Bruns, and D. Bräunig, "Electroreflectance of $\mathrm{CuInS}_{2}$ thin film solar cells and dependence on process parameters," Journal of Applied Physics, vol. 89, no. 5, pp. 3049-3054, 2001.

[6] R. G. Rodrigues, I. Bhat, J. M. Borrego, and R. Venkatasubramanian, "Photoreflectance characterization of InP and GaAs solar cells," in Proceedings of the 23rd IEEE Photovoltaic Specialists Conference, pp. 681-685, Louisville, Ky, USA, May 1993.

[7] D. Y. Lin, W. C. Lin, F. L. Wu et al., "Investigations of interdiffusion in InGaAsP multiple-quantum-well structures by photoreflectance," Physica Status Solidi A, vol. 206, no. 5, pp. 791-795, 2009.
[8] D. Y. Lin, Y. S. Huang, T. S. Shou, K. K. Tiong, and F. H. Pollak, "Temperature-dependent contactless electroreflectance and photoluminescence study of GaAlAs/InGaAs/GaAs pseudomorphic high electron mobility transistor structures," Journal of Applied Physics, vol. 90, no. 12, pp. 6421-6427, 2001.

[9] J. Y. Zheng, D. Y. Lin, and Y. S. Huang, "Piezoreflectance study of band-edge excitons of $\mathrm{ReS}_{2}$ : Au," Japanese Journal of Applied Physics, vol. 48, Article ID 052302, 2009.

[10] F. H. Pollak, H. Qiang, D. Yan, W. Krysten, and S. Moneger, "Contactless electromodulation for the nondestructive, roomtemperature analysis of wafer-sized semiconductor device structures," IEEE Journal of Selected Topics in Quantum Electronics, vol. 1, no. 4, pp. 1002-1010, 1995.

[11] D. Y. Lin, J. D. Wu, C. C. Hung et al., "Optical investigation of an $\mathrm{AlGaN} / \mathrm{GaN}$ interface with the presence of a twodimensional electron gas," Physica E: Low-Dimensional Systems and Nanostructures, vol. 43, no. 1, pp. 125-129, 2010.

[12] S. Kamiyama, T. Uenoyama, M. Mannoh, Y. Ban, and K. Ohnaka, "Analysis of GaInP/AlGaInP compressive strained multiple-quantum-well laser," IEEE Journal of Quantum Electronics, vol. 30, no. 6, pp. 1363-1369, 1994.

[13] Y. Yu, X. Zhang, B. Huang et al., "Strain effect and characteristics of GaInP/AlGaInP strain-compensated multiple quantum wells," Materials Science and Engineering: B, vol. 97, no. 3, pp. 211-216, 2003.

[14] D. Y. Lin, Y. S. Huang, and K. K. Tiong, "A second-harmonic electroreflectance study of a coupled GaAs-AlGaAs double quantum well," Semiconductor Science and Technology, vol. 12, no. 9, pp. 1111-1115, 1997.

[15] H. I. Ralph, "On the theory of the Franz-Keldysh effect," Journal of Physics C: Solid State Physics, vol. 1, no. 2, p. 378, 1968.

[16] H. Shen and F. H. Pollak, "Generalized Franz-Keldysh theory of electromodulation," Physical Review B, vol. 42, no. 11, pp. 7097$7102,1990$.

[17] H. Shen and M. Dutta, "Franz-Keldysh oscillations in modulation spectroscopy," Journal of Applied Physics, vol. 78, no. 4, pp. 2151-2176, 1995.

[18] C. H. Chan, M. C. Chen, H. H. Lin, Y. F. Chen, and G. J. Jan, "Characterization of piezoelectric (111)B InGaAs/GaAs p-i-n quantum well structures using photoreflectance spectroscopy," Applied Physics Letters, vol. 72, article 1208, 1998.

[19] C. H. Chan, Y. F. Chen, M. C. Chen, H. H. Lin, G. J. Jan, and Y. H. Chen, "Photoreflectance spectroscopy of strained-layer (111)B InGaAs/GaAs quantum well diodes," Journal of Applied Physics, vol. 84, no. 3, pp. 1595-1601, 1998.

[20] Y. S. Huang and F. H. Pollak, "Non-destructive, room temperature characterization of wafer-sized III-V semiconductor device structures using contactless electromodulation and wavelength-modulated surface photovoltage spectroscopy," Physica Status Solidi A, vol. 202, no. 7, pp. 1193-1207, 2005.

[21] T. J. C. Hosea, S. A. Cripps, T. E. Sale, and K. Hild, "Analysis of reflectance and modulation spectroscopic lineshapes in optoelectronic device structures," Applied Surface Science, vol. 253, no. 1, pp. 70-79, 2006.

[22] A. Podolian, V. Kuryliuk, and O. Korotchenkov, "Rf straincontrolled built-in electric field near $\mathrm{SiO}_{2} / \mathrm{SiGe}$ interface," Solar Energy Materials and Solar Cells, vol. 93, no. 11, pp. 1946-1951, 2009.

[23] X. J. Shang, J. F. He, H. L. Wang et al., "Effect of built-in electric field in photovoltaic InAs quantum dot embedded GaAs solar cell," Applied Physics A, vol. 103, no. 2, pp. 335-341, 2011. 
[24] K. W. J. Barnham, B. Braun, J. Nelson et al., "Short-circuit current and energy efficiency enhancement in a low-dimensional structure photovoltaic device," Applied Physics Letters, vol. 59, no. 1, pp. 135-137, 1991.

[25] M. Chegaar, Z. Ouennoughi, F. Guechi, and H. Langueur, "Determination of solar cells parameters under illuminated conditions," Journal of Electron Devices, vol. 2, pp. 17-21, 2003.

[26] M. J. Morgan, G. Jakovidis, and I. McLeod, "An experiment to measure the I-V characteristics of a silicon solar cell," Physics Education, vol. 29, no. 4, pp. 252-254, 1994.

[27] P. Štulík and J. Singh, "A simple method to simulate the influence of defects on the short circuit current in amorphous silicon solar cells," Journal of Non-Crystalline Solids, vol. 226, no. 3, pp. 299303, 1998.

[28] T. Tayagaki, Y. Hoshi, and N. Usami, "Investigation of the opencircuit voltage in solar cells doped with quantum dots," Scientific Reports, vol. 3, article 2703, 2013.

[29] T. Taima, M. Chikamatsu, Y. Yoshida, K. Saito, and K. Yase, "Effects of intrinsic layer thickness on solar cell parameters of organic p-i-n heterojunction photovoltaic cells," Applied Physics Letters, vol. 85, no. 26, pp. 6412-6414, 2004.

[30] G. W. Shu, J. J. Yang, I. J. Shu et al., "Dependence of biasing voltage and illumination power on the built-in electric field of InGaP solar cells," Japanese Journal of Applied Physics, vol. 51, no. 7, Article ID 072301, 2012. 

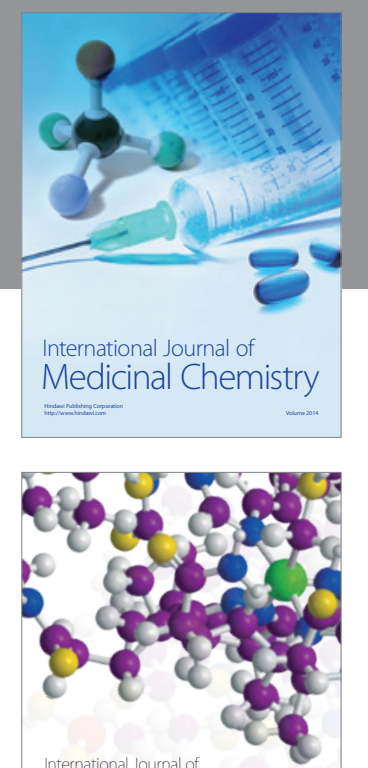

\section{Carbohydrate} Chemistry

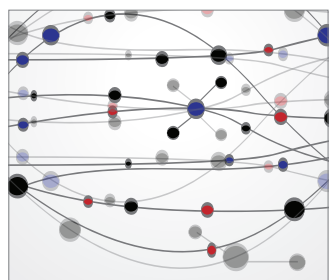

The Scientific World Journal
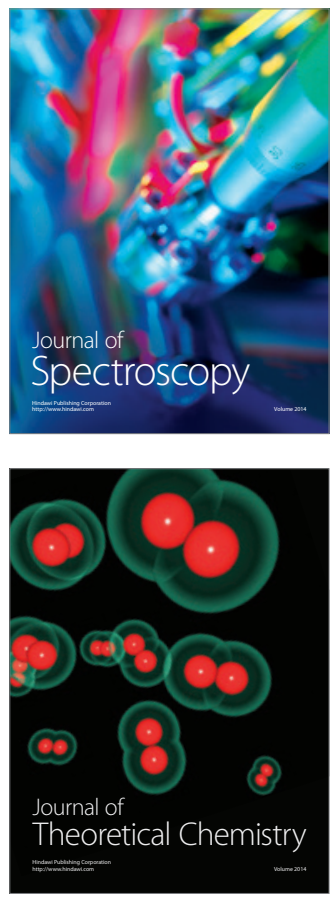
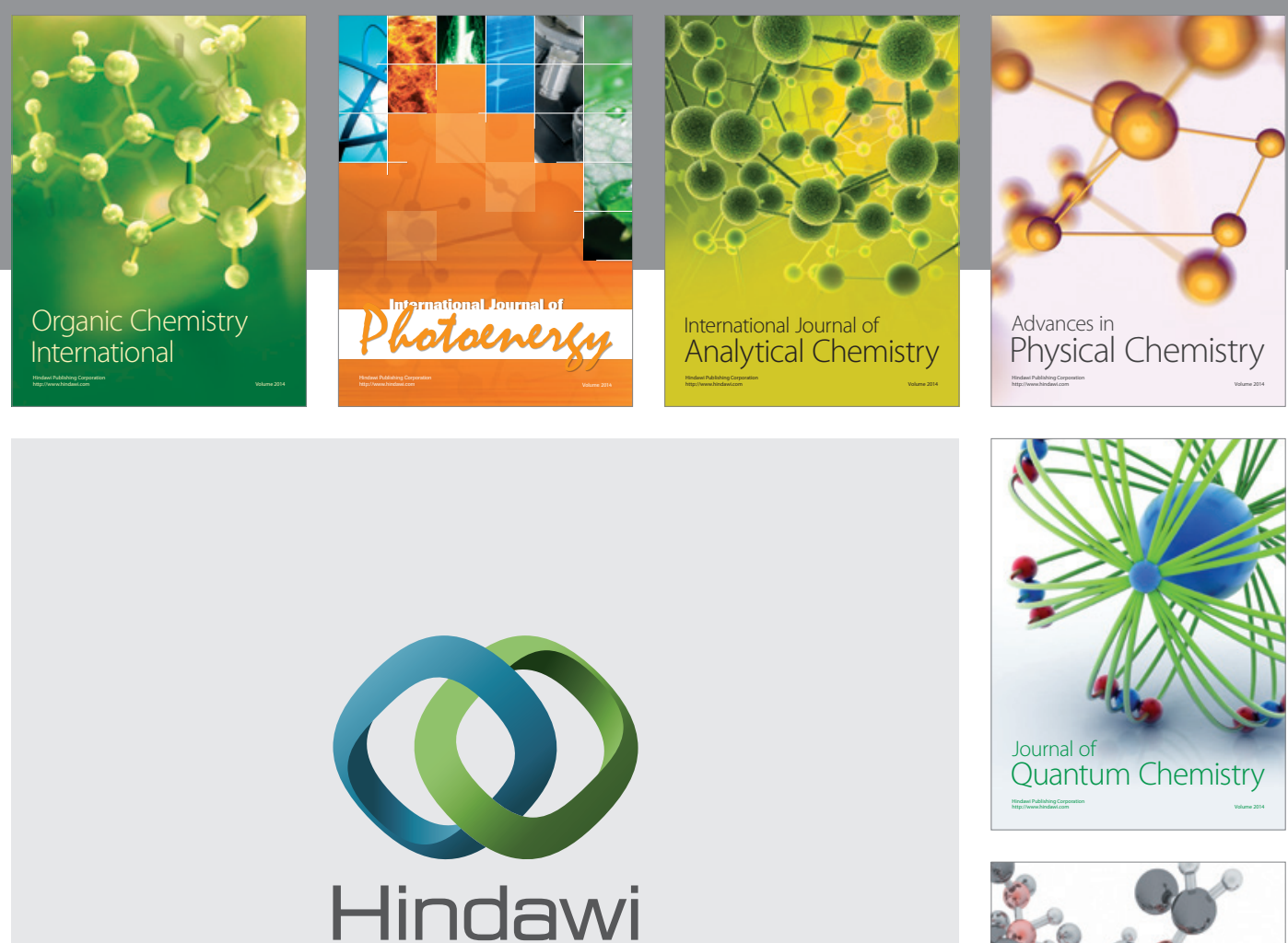

Submit your manuscripts at

http://www.hindawi.com

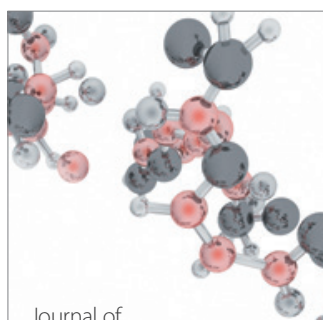

Analytical Methods

in Chemistry

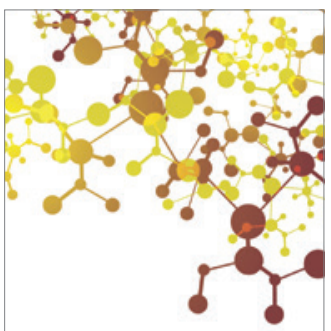

Journal of

Applied Chemistry

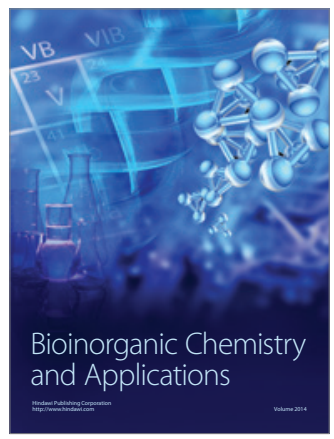

Inorganic Chemistry
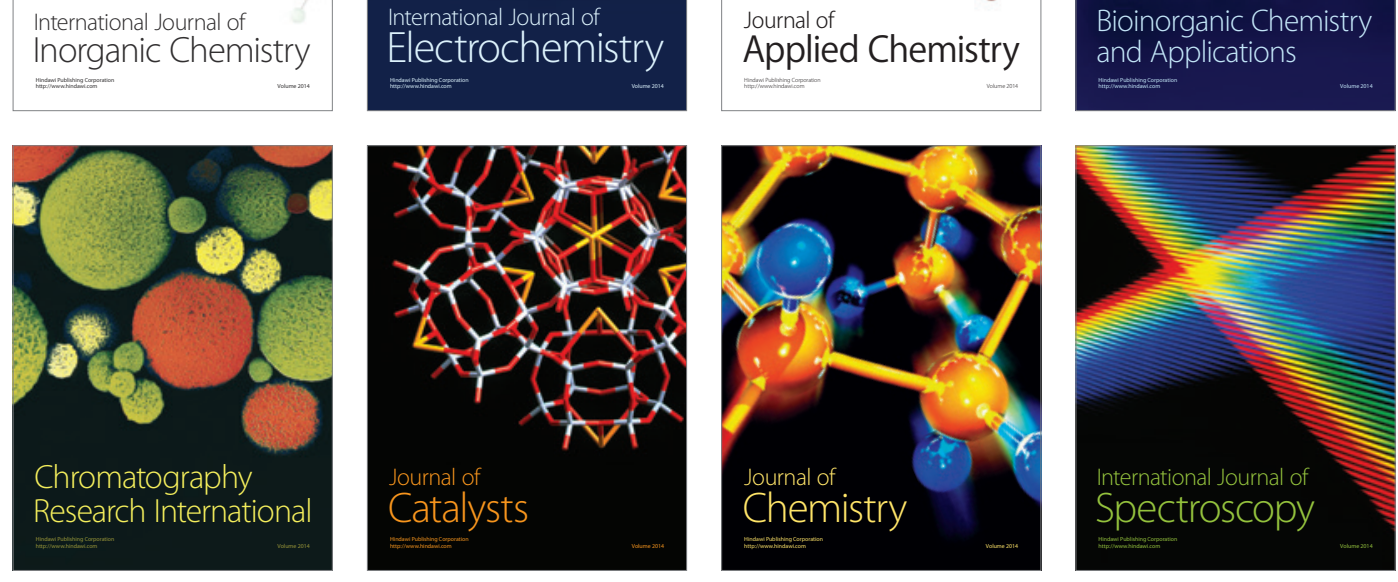